\title{
INTRODUCTION 1946 (English Version)
}

When a not inconsiderable part of our international relations had been broken off at the end of the year 1939 we decided to stop the publication of our journal. For in our opinion an international exchange of information must not degenerate into one-sided information, into a propagating of one distinct view of life and of the world. However, when free utterance of thought was no longer possible, the abovementioned decision did not prevent our continuing our work within the frontiers of our country and chiefly on the subject of the analysis of concepts. The International Group for the Study of Significs, so closely associated with our magazine, has been able to continue its activities even during the years of the occupation, albeit as an illegally existing society with Dutch members only. In the beginning its reports could even be distributed to the members fairly regularly.

As to our periodical we may say the following. Started in Holland and rooted in Dutch soil, it has been able to extend its sphere of influence considerably in the course of years. That could not well be otherwise. For Synthese did not want to be only a passive reproduction of the different cultural tendencies and trends which dominate international cultural life, it also wanted to take part in the marking out of a course, in co-operating to restore to health a spiritual life, which as we need not explain here - showed many signs of deterioration and degeneration before the second world-war.

In post-war thought two large spheres of influence are marking themselves off clearly: an Anglo-American and a Russian one, and perhaps we may say that in Central Europe these two spheres touch.... we dare not yet say that they interpenetrate each other. Moved by these and other considerations we have decided to give an important place in our journal to the representatives of these spheres of culture. It appears to us that, because of their geographical position and their historical tradition in matters of culture, the Netherlands are particularly suited to serve as a common meeting-ground. In separate sections ranged on the one hand according to the subject, on the other hand according to the country of origin of the author, we shall try to give expression to this new aim. Our own contribution will consist in the integration of the instruments of thought which the different spheres of culture make use of.

We had undertaken such a task of integration already before the war. We placed our columns at the disposal of representatives of divergent trends of thought: the mystical-religious trend was represented in our journal as well as the axiomatic-formalistic one and our attention was likewise devoted to the school of thought lying in between, one might call it the psychological-relativistic one. But we tried to avoid going to extremes. As regards the speculative trends finding expression for instance, in the off-shoots of Neo-Kantianism, in Phenomenology, in "Existenz-philosophie" and in some forms of Neo-Vitalism, all of them be- 
ing predominantly a form of word-thinking caring little or nothing about the verification of its statements, they have often induced us to point out the great danger attached to such a spiritual attitude for uncritical minds. On the other hand we were not swayed by extreme axiomatic tendencies, aiming at an index verborum prohibitorum, a list of prohibited words, consequently a dictatorial censorship. Those manifesting such tendencies - physicists for the most part - were apt to claim for the observation-statements the monopoly of the means of grace even in the region of the sciences of life. Therefore, we always greatly sympathized with the tendency, increasingly revealing itself in science and philosophy, to shift from speculation to verification, from devices to description.

We have mentioned above the two strong influences dominating present-day international cultural life: the Russian and the Anglo American one. The sphere of culture of Eastern Europe is for the greater part as yet unknown to the West European. Prejudiced in this regard, either because he has been wrongly and superficially informed (whether intentionally or not) or because he is ignorant, he is usually accessible only to such new ideas as his often one-sided education and schooling has prepared him to assimilate. An important part of the culture of the world is in this way lost to him. A short time before the war however, a turning of the tide was becoming evident in this respect and then already we tried to break with that deplorable tradition in spite of the constant menace of approaching war. But it is only now that we have succeeded in creating for our readers an opportunity of acquiring an insight into the development and the possibilities of development of Russian culture and science, thanks to the co-operation of Russian authorities both in this country and in Moscow. We hope that as a result, the character of one-sided information will be radically changed in our country too, even if on this one point only. This will greatly benefit the furtherance of international thought and of international cultural relations for which Synthese has stood in the breach from the day of its first appearance.

From the side of the British and American authorities too all possible assistance has been rendered us, which facilitated the carrying through of our projects. To this assistance the newly opened British section hears witness and we trust that the development of our pre-war relations with the U.S.A. will convincingly prove the same.

We should like to call the attention of our readers to yet another item of our program. The six years lying behind us have been very instructive. It was a period in which those spirits often had much to endure, which had been rendered incapable of critical thinking by bad educational methods. Apart from the deficient development of the critical element in our educational system, we think that this phenomenon is due for a not inconsiderable part to the great arrears in the develojment of the sciences of man (les sciences de l'homme) as compared with that of the sciences of nature. To take some subjects 
at random: mass-psychology, mass-psychiatry and psychology of understanding are only just beginning to draw the attention of serious investigators. The apparatus for influencing the masses cannot possibly be kept outside the sphere of scientific inquiry any longer. The methods which have created and perfected the sciences of nature in the course of three centuries will enable us to evolve the sciences of man (or at any rate to bring them into a form of appropriate applicability) in a much shorter time. With the help of the latter sciences it will be possible to determine with more or less accuracy the conditions of internal equilibrium of the separate individuals and the exterior psychological, economic, political and social conditions of equilibrium in the relations between individuals. In the future this may form the foundation of a scientific sociology, nay, of politics which will then be a science and no longer a confused appeal to ancient instincts bound to complexes of hate and rejection. We are of opinion that these arrears constitute a danger to the harmonious mental evolution of mankind. And on this opinion was based our pre-war co-operation with the "Centre d'Etudes des Problèmes Humains" of Paris, for which we were to have read a paper, the text of which we are now printing in our French section (cf. also the journal of the Centre "Humanisme Economique" 1938 13/14). Thus Synthese hopes to be able to continue fulfilling its informative task. The idea of international cultural co-operation which this journal put into practice in the year 1936 proved to be sufficiently fruitful to be imitated in our country. And it is with satisfaction that we ascertain that a part of our intellectual world was open to the influence of the analysis of concepts, a working-method which was introduced and applied by us in close co-operation with the International Group for the Study of Significs (present name: International Society for the Study of Significs). We now intend to continue our work on the same lines extending our program of action according to need and occasion, for the attainment of one of our chief aims: the establishment and development of Anglo-American-Russo-West European cultural co-operation.

December 1945

The Editors. 